\title{
Effect of total flavonoids from Drynaria rhizome on bone loss in ovariectomized rats
}

\author{
ZhengNan Zhao, XiangLong Yang, Fang Yu, WenJi Song, HaiDong Liang* \\ Department of Hand and Foot Microsurgery, The Second Hospital of Dalian Medical University, Dalian, Liaoning 116023, China
}

*For correspondence: Email: lianghddlf@sina.com

Sent for review: 9 January 2019

Revised accepted: 20 June 2019

\begin{abstract}
Purpose: To determine the potential effect of total flavonoids from Drynaria rhizome on bone loss in ovariectomized (OVX) rats.

Methods: The rats were divided into four groups: normal control, ovariectomized (OVX) control, and two Drynaria rhizome (DR) flavonoids treatments. Post-operation, osteoporotic OVX rats were given Drynaria rhizome total flavonoids for 3 months. Thereafter, the expressions of bone-related genes and biochemical indices were investigated in samples taken from the serum and bone of the rats.

Results: Treatment with total flavonoids from Drynaria rhizome prevented bone mineral loss and improved some related biochemical indices associated with osteoporosis: alkaline phosphatase $(A L P)$, tartrate-resistant acid phosphatase (TRAP), bone gla protein (BGP) and estradiol (E2). Reverse transcription-polymerase chain reaction (RT-PCR) data showed that treatment with the total flavonoids significantly downregulated mRNA expression of Wnt10b, $\beta$-catenin, recombinant human bone morphogenetic protein-2 (BMP2) and BMP4 in OVX rats, but significantly reversed OVX-induced downregulation of dickkopf1 (Dkk1) mRNA expression.

Conclusion: These results indicate that total flavonoids from Drynaria rhizome exert anti-osteoporotic effects in rats via WNT signaling and BMP-2 signaling pathways.
\end{abstract}

Keywords: Drynaria rhizome, Bone loss, Total flavonoids, Ovariectomized rats, BMP-2 signaling pathway

\begin{abstract}
This is an Open Access article that uses a fund-ing model which does not charge readers or their institutions for access and distributed under the terms of the Creative Commons Attribution License (http://creativecommons.org/licenses/by/4.0) and the Budapest Open Access Initiative (http://www.budapestopenaccessinitiative.org/read), which permit unrestricted use, distribution, and reproduction in any medium, provided the original work is properly credited.

Tropical Journal of Pharmaceutical Research is indexed by Science Citation Index (SciSearch), Scopus, International Pharmaceutical Abstract, Chemical Abstracts, Embase, Index Copernicus, EBSCO, African Index Medicus, JournalSeek, Journal Citation Reports/Science Edition, Directory of Open Access Journals (DOAJ), African Journal Online, Bioline International, Open-J-Gate and Pharmacy Abstracts
\end{abstract}

\section{INTRODUCTION}

Osteoporosis is a concomitant of old age and a source of serious debilitation due to increased incidence of bone breakages, deterioration in life quality or even mortality $[1,2]$. It is a disease of global concern which affects more than 200 million people yearly [3-5]. Studies have revealed that $30 \%$ of females and $20 \%$ of males above the age of 50 experience bone fractures [5].
Osteoporosis occurs mostly in women who have attained menopause, a condition termed postmenopausal osteoporosis.

Drynaria rhizome is a fern native to China. Its rhizomes are essential components of a popular Traditional Chinese Medicine for treating osteoporosis and fractures [6]. Previous phytochemical investigations reported the isolation of some triterpenoids and flavonoids 
from Drynaria rhizome [7]. Recently, it was reported that naringin, one of the key phytochemicals present in Drynaria rhizome, improves bone quality in retinoic acid-induced osteoporosis [8], and in orchidectomized rat models [9]. These findings confirmed that naringin is one of the active principles that account for the osteo-protective effects of Drynaria rhizome. In addition, naringin markedly enhanced proliferation, total protein concentration and ALP activities of rat osteoblastic-like UMR 106 cells [10].

Studies on the phytochemical constituents of Drynaria rhizome have revealed that the predominant compounds are flavonoids, and researchers have focused on these with respect to their anti-osteoporotic properties [11]. The major flavonoids of Drynaria rhizome are neoeriocitrin and naringin [12].

In this study, the anti-osteoporotic effect Drynaria rhizome total flavonoids in rats, and the underlying mechanism, were investigated.

\section{EXPERIMENTAL}

\section{Animals}

Eight-week-old female Wistar rats weighing 250 - $300 \mathrm{~g}$ were stabilized and conditioned to laboratory environment for 7 days prior to commencement of the study. The experiments were conducted in accordance with the International guidelines for study of laboratory animals [13], and permitted by the local ethical committee (approval no. 20170628).

\section{Osteoporotic rat model}

Following $6 \mathrm{~h}$ fast, ovaries were excised from the rats under pentobarbital anesthesia $(50 \mathrm{mg} / \mathrm{kg}$ i.p.). In normal control rats, oophorectomy was not done. At the end of the operation, the rats received gentamicin treatment intramuscularly for 3 days successively. After 16 weeks, the animals were grouped into 4 , with 8 rats per group: sham control, oophorectomized control (oophorectomy without treatment); low-dose total flavonoids from Drynaria rhizome treatment $(0.3 \mathrm{~g} / \mathrm{kg})$; and high dose total flavonoids from Drynaria rhizome treatment $(0.5 \mathrm{~g} / \mathrm{kg})$ groups. Rats in the last two groups were given Drynaria rhizome total flavonoids for 3 months through the oral route.

\section{Biochemical assays}

Bone alkaline phosphatase (BALP) and TRAP were assayed with ELISA kits according to the protocol of the kit manufacturers.

\section{Determination of bone mineral density (BMD)}

Bone mineral density was assessed prior to operation (baseline) and post-treatment through femur bone scan with dual-energy X-ray absorptiometry (GE Lunar Prodigy, Chicago) at 1 $\mathrm{mm} / \mathrm{sec}$ and $0.5 \times 0.5 \mathrm{~mm}$ resolution. The mean of 3 repeated measurements was used in order to eliminate repositioning errors. Bone mineral density (BMD) was calculated and presented in $\mathrm{mg} / \mathrm{cm}^{2}$.

\section{Determination of bone gla protein (BGP), estradiol (E2) and OPG}

Serum estradiol, bone gla protein and OPG were determined with their respective ELISA kits (WuHan HuaMei Company, China), in line with the protocols specified in the kit manuals.

\section{RT-PCR}

Table 1: Genes and sequence

\begin{tabular}{|c|c|}
\hline No & Gene Sequences \\
\hline Wnt10b & Sense: 5'-GTAATCACGACATGGACTTTGGAG-3' \\
\hline$\beta$-catenin & $\begin{array}{l}\text { Antisense: 5'-GCACTTCCGCTTCAGGTTTTT-3' } \\
\text { Sense' 5'-ATGCGGCTGCTGTTCTATTC-3' }\end{array}$ \\
\hline$p$-caleriml & Antisense: 5'-ACCAATGTCCAGTCCGAGAT-3' \\
\hline BMP2 & $\begin{array}{l}\text { Sense: 5'-GGATTAGCAGGTCTTTGCACCA-3', } \\
\text { Antisense: 5'-GCTTGACGC TTTTCTCGTTTG-3' }\end{array}$ \\
\hline BMP4 & $\begin{array}{l}\text { Sense: 5'-ACAATGTGACACGGTGGGAAAC-3' } \\
\text { Antisense: 5'-TGTGGGTGATGCTTGGGACTAC-3' }\end{array}$ \\
\hline Dkk1 & $\begin{array}{l}\text { Sense: 5'-GCTCTGTCTGCCTCCGATCA-3 } \\
\text { Antisense: 5'-GCCTTTCCTCCTGTGCTTGG-3' }\end{array}$ \\
\hline GAPDH & $\begin{array}{l}\text { Sense: 5'-AAGATGGTGAAGGTCGGTGT-3' } \\
\text { Antisense: 5'-CTTGCCGTGGTAGAGTCAT-3' }\end{array}$ \\
\hline
\end{tabular}

Bone cell total RNA extraction was done with TRIzol reagent (Invitrogen, USA), and $2 \mu \mathrm{g}$ of the RNA extract was subjected to reversetranscription to cDNA with RevertAid First Strand cDNA Synthesis Kit (Thermo Fisher Scientific, USA). Polymerase chain reaction was carried out using ABI 7300 RealTime PCR System. The sequences of the primers used are shown below (Table 1). The PCR conditions were: initial denaturation at $95{ }^{\circ} \mathrm{C}$ for $10 \mathrm{~min}$, then 40 cycles at $95{ }^{\circ} \mathrm{C}$ for $15 \mathrm{sec}$, and at $60^{\circ} \mathrm{C}$ for $30 \mathrm{sec}$. Gene expressions relative to $\beta$-actin, were computed with the $2^{-\Delta \Delta C t}$ procedure.

\section{Statistical analysis}

Results are presented as mean \pm SEM. Statistical analysis was carried out with SPSS version 17.0. Groups were compared using oneway ANOVA with post hoc LSD test. Values of $p$ $<0.05$ were taken as indicative of statistical significance. 


\section{RESULTS}

\section{Serum ALP and TRAP}

Oophorectomy led to significant increases in serum levels of ALP and TRAP, when compared with normal control $(p<0.001)$. However, the administration of total flavonoids from Drynaria rhizome $(0.3$ and $0.5 \mathrm{~g} / \mathrm{kg})$ dose-dependently and significantly decreased the ALP and TRAP, when compared to untreated OVX rats (Table 2).

Table 2: Effect of total flavonoids from Drynaria rhizome on ALP and TRAP levels (U/L)

\begin{tabular}{lcc}
\hline Group & ALP & TRAP \\
\hline Normal control & $30.72 \pm 2.31$ & $2.74 \pm 0.17$ \\
OVX control & $49.62 \pm 2.72^{* *}$ & $4.53 \pm 0.23^{*}$ \\
OVX + DR flavonoids & $40.63 \pm 3.06^{\#}$ & $3.91 \pm 0.18^{\# \#}$ \\
$(0.3 \mathrm{~g} / \mathrm{kg})$ & & \\
OVX+ DR flavonoids & $33.28 \pm 2.15^{\# \#}$ & $3.05 \pm 0.266^{\# \#}$ \\
$(0.5 / \mathrm{kg})$ & & \\
\hline${ }^{*} P<0.05$, relative to normal control; ${ }^{\#} p<0.05,{ }^{\# \#} p<$ \\
0.01, relative to OVX control
\end{tabular}

\section{Effect of Drynaria rhizome total flavonoids on BMD of OVX rats}

Table 3 shows that oophorectomy brought about significant reduction in femoral BMD of OVX rats after 3 months, relative to normal control rats. However, after 3 months of administration of total flavonoids from Drynaria rhizome (0.3 and 0.5 $\mathrm{g} / \mathrm{kg}$ ), there were significant and dose-influenced enhancement of BMD in femurs of the OVX rats $(p<0.05, p<0.01)$.

Table 3: Effect of total flavonoids from Drynaria rhizome on BMD levels

\begin{tabular}{ll}
\hline Group & $\begin{array}{l}\text { Bone mineral } \\
\text { density }\left(\mathbf{g} / \mathbf{c m}^{2}\right)\end{array}$ \\
\hline Normal control & $0.2389 \pm 0.0217$ \\
OVX control & $0.1948 \pm 0.01311^{* *}$ \\
OVX+ DR flavonoids $(0.3 \mathrm{~g} / \mathrm{kg})$ & $0.2152 \pm 0.0184^{\#}$ \\
OVX+ DR flavonoids $(0.5 / \mathrm{kg})$ & $0.2347 \pm 0.0175^{\# \#}$ \\
\hline${ }^{*} P<0.05$, relative to normal control; ${ }^{\#} p<0.05,{ }^{\# \#} p<$ \\
0.01 , relative to untreated OVX
\end{tabular}

\section{Effect of total flavonoids from Drynaria rhizome on E2 and GBP}

There were significantly higher levels of serum
BGP in rats in untreated OVX group than in normal control rats. Significant reductions in serum E2 were seen in untreated OVX rats, when compared with normal control rats. However, serum BGP levels were significantly decreased by treatment with total flavonoids from Drynaria rhizome at both doses $(0.3$ and 0.5 $\mathrm{g} / \mathrm{kg}$ ), relative to untreated OVX group. In addition, treatment with the total flavonoids from Drynaria rhizome at both doses $(0.3$ and 0.5 $\mathrm{g} / \mathrm{kg}$ ) led to significant elevation of serum E2, when compared with the OVX control group. These results are presented on Table 4.

Table 4: Effect of total flavonoids from Drynaria rhizome on BGP and E2 levels $(\mu \mathrm{g} / \mathrm{L})$

\begin{tabular}{lll}
\hline Group & BGP & E2 \\
\hline Normal control & $14.297 \pm 1.25$ & $16.382 \pm 1.38$ \\
OVX control & $35.821 \pm 2.62^{\star \star}$ & $10.042 \pm 0.93^{\star \star}$ \\
OVX+DR flavonoids & $27.206 \pm 1.96 \# \# 13.628 \pm 0.93 \# \#$
\end{tabular}

$(0.3 \mathrm{~g} / \mathrm{kg})$

OVX+DR flavonoids $\quad 16.825 \pm 1.18 \# \# 15.424 \pm 1.05 \# \#$ $(0.5 \mathrm{~g} / \mathrm{kg})$

${ }^{\star} P<0.05$, relative to normal control; \#\#p<0.01, relative to OVX control

Effect of total flavonoids from Drynaria rhizome on expressions of bone-associated genes

Bilateral oophorectomy markedly enhanced the expressions of Wnt10b, $\beta$-catenin, BMP2, BMP4 mRNAs, while Dkk1 mRNA expression was markedly downregulated $(p<0.01)$, when compared to the normal control group (Table 5). As expected, treatment with total flavonoids from Drynaria rhizome $(0.3$ and $0.5 \mathrm{~g} / \mathrm{kg})$ significantly downregulated mRNA expressions of Wnt10b, $\beta$ catenin, BMP2, BMP4 in OVX rats, but significantly reversed OVX-induced downregulation of Dkk1 mRNA expression (Table 5).

\section{DISCUSSION}

The level of osteoclast isoenzyme of ALP is often employed as an index of degree of differentiation of osteoblasts. Indeed, TRAP serves as a specific parameter for functionality of osteoclasts [14]. The reduction in TRAP activity in rats

Table 5: Effect of total flavonoids from Drynaria rhizome on mRNA expressions of Wnt10b, $\beta$-catenin, BMP2, BMP4, and Dkk1

\begin{tabular}{lccccc}
\hline Group & Wnt10b & $\boldsymbol{\beta}$-catenin & BMP2 & BMP4 & Dkk1 \\
\hline Normal control & $1.00 \pm 0.00$ & $1.0 \pm 0.0$ & $1.0 \pm 0.0$ & $1.0 \pm 0.0$ & $1.0 \pm 0.0$ \\
OVX control & $1.7 \pm 0.1^{* *}$ & $1.5 \pm 0.1^{* *}$ & $1.6 \pm 0.1^{* *}$ & $1.6 \pm 0.1^{* *}$ & $0.6 \pm 0.0^{* *}$ \\
OVX+DR flavonoids $(0.3 \mathrm{~g} / \mathrm{kg})$ & $1.5 \pm 0.1^{\# \#}$ & $1.5 \pm 0.1^{\# \#}$ & $1.5 \pm 0.1^{\# \#}$ & $1.3 \pm 0.1^{\# \#}$ & $0.8 \pm 0.1^{\# \#}$ \\
OVX+ DR flavonoids $(0.5 \mathrm{~g} / \mathrm{kg})$ & $1.2 \pm 0.1^{\# \#}$ & $1.2 \pm 0.1^{\# \#}$ & $1.3 \pm 0.1^{\# \#}$ & $1.2 \pm 0.1^{\#}$ & $1.2 \pm 0.1^{\# \#}$ \\
\hline
\end{tabular}

${ }^{\star} P<0.05$, relative to normal control; ${ }^{\# \#} p<0.01$, relative to untreated OVX group 
treated with total flavonoids from Drynaria rhizome suggests that total flavonoids from Drynaria rhizome suppress the function of osteoclasts.

In addition, the total flavonoids from Drynaria rhizome influenced serum ALP levels. These findings indicate that total flavonoids from Drynaria rhizome have obvious effect on osteoblast differentiation. Thus, total flavonoids from Drynaria rhizome may decrease bone loss.

Low levels of estrogens result in bone demineralization and osteoporosis [15]. In the present study, total flavonoids from Drynaria rhizome markedly blocked oophorectomyinduced reduction in $E_{2}$, indicating that the flavonoids possess phytoestrogenic potential. Serum BGP and OPG are used as markers of bone turnover [16]. In this study, ALP level (index of osteogenesis) was enhanced by treatment of OVX rats with total flavonoids from Drynaria rhizome. The results also showed that total flavonoids from Drynaria rhizome significantly decreased serum BGP in oophorectomized rats, suggesting that the flavonoids can increase osteogenesis while inhibiting osteoporosis. These findings explain the marked enhancement of bone mineral density of femur in the oophorectomized rats treated with total flavonoids from Drynaria rhizome.

The association of Wnt10b with various diseases has been extensively reviewed [17]. The Wntsignaling route is a key factor involved in regulation of bone metabolism via enhancement of osteogenesis. When $\mathrm{Wnt} / \beta$-catenin signal route is activated, precursor cells to osteoblasts proliferate and differentiate, and apoptotic changes in mature osteoblasts decrease, resulting in suppression of the osteoblastinduced inhibition of the ability of the osteoclasts to differentiate [18-20]. A large corpus of evidence have demonstrated that Dkk1 plays an important role in limb morphogenesis and head induction [21,22], and also in osteogenesis and bone disease. The BMPs facilitate osteogenesis in neonates. Studies on post-natal mice have shown that impairment of BMP function resulted in fragile bones and increased tendency to unprovoked fractures [23].

In the current study, total flavonoids from Drynaria rhizome significantly downregulated mRNA expressions of Wnt10b, $\beta$-catenin, BMP2 and BMP4 in oophorectomized rats, and markedly blocked OVX-associated downregulation of Dkk1 mRNA expression. The results indicate that the mechanism involved in the promotion of osteoblast proliferation in osteoporosis by total flavonoids from Drynaria rhizome is closely related to upregulation of mRNA expressions of Wnt10b, $\beta$-catenin, BMP2 and BMP4, and downregulation of Dkk1 mRNA expression. In addition, total flavonoids from Drynaria rhizome induce osteoblast proliferation possibly by regulating the relationship between classical WNT signaling pathway and BMP-2 signaling pathway.

\section{CONCLUSION}

The findings in this study suggest that total flavonoids from Drynaria rhizome reduce bone loss by decreasing ALP, TRAP and BGP levels, while increasing the production of BMD and $E_{2}$. Thus, these results demonstrate, for the first time, that the total flavonoids from Drynaria rhizome alleviate osteoporosis, in part, by regulating the relationship between classical WNT signaling and BMP-2 signaling pathways.

\section{DECLARATIONS}

\section{Conflict of interest}

No conflict of interest is associated with this work.

\section{Contribution of authors}

The authors affirm that this study was carried out by those whose names appear in this manuscript, and that all liabilities arising from claims in respect of the manuscript content will be the sole responsibility of the authors.

\section{Open Access}

This is an Open Access article that uses a funding model which does not charge readers or their institutions for access and distributed under the terms of the Creative Commons Attribution License (http://creativecommons.org/licenses/by/ 4.0) and the Budapest Open Access Initiative (http://www.budapestopenaccessinitiative.org/rea d), which permit unrestricted use, distribution, and reproduction in any medium, provided the original work is properly credited.

\section{REFERENCES}

1. Comelekoglu U, Bagis S, Yalin S, Ogenler O, Yildiz A, Sahin NO, Oguz l, Hatungil R. Biomechanical evaluation in osteoporosis: ovariectomized rat model. Clin. Rheumatol 2007; 26 (3): 380-384

2. Cheng N, Dai J, Cheng X, Li S, Miron RJ, Wu T, Chen W, Zhang $Y$, Shi B. Porous CaP/silk composite scaffolds to 
repair femur defects in an osteoporotic model. J. Mater. Sci. Mater. Med., 2013; 24 (8): 1963-1975

3. Johnell $O$, Kanis JA. An estimate of the worldwide prevalence and disability associated with osteoporotic fractures. Osteoporos. Int., 2006; 17 (12): 1726-1733.

4. Meimandi-Parizi A, Oryan A, Sayahi E, Bigham-Sadegh A. Propolis extract a new reinforcement material in improving bone healing: An in vivo study. Int J Surg, 2018; 56: 94-101

5. Calcei JG, Rodeo SA. Orthobiologics for Bone Healing. Clinics in Sports Medicine, 2019; 38: 79-95

6. China Pharmacopoeia Committee Pharmacopoeia of the People's Republic of China (2005 ed.), Chemical Industry Press, Beijing (2005), p. 179

7. Chang EJ, Lee WJ, Cho SH, Choi SW. Proliferative effects of flavan-3-ols and propelargonidins from rhizomes of Drynaria fortunei on MCF-7 and osteoblastic cells. Arch Pharm Res, 2003; 26: 620-630

8. Wei $M$, Yang $Z$, Li $P$, Zhang $Y$, Sse WC. Antiosteoporosis activity of naringin in the retinoic acidinduced osteoporosis model. Am. J. Chin. Med., 2007; 35: 663-667

9. Mandadi K, Ramirez M, Jayaprakasha GK, Faraji $B$, Lihono M, Deyhim F, Patil BS. Citrus bioactive compounds improve bone quality and plasma antioxidant activity in orchidectomized rats. Phytomedicine, 2009; 16: 513-520

10. Wong RW, Rabie AB. Effect of naringin on bone cells. J. Orthop. Res., 2006; 24: 2045-2050

11. Wang XL, Wang NL, Zhang Y, Gao H, Pang WY, Wong MS. Effects of eleven flavonoids from the osteoprotective fraction of Drynaria fortune (KUNZE) J. SM. on osteoblastic proliferation using an osteoblast-like cell line. Chem. Pharm. Bull. (Tokyo), 2008; 56: 46-51

12. Xu T, Wang L, Tao $Y$, Ji $Y$, Deng $F, W u X H$. The function of naringin in inducing secretion of osteoprotegerin and inhibiting formation of osteoclasts. Evid. Based Complement. Altern. Med., 2016; 2016: 8981650

13. Garber JC (Chair). Committee for the Update of the Guide for the Care and Use of Laboratory Animals. Guide for the Care and Use of Laboratory Animals, eighth ed. Washington DC, USA: National Academy of Sciences; 2011.
14. Choi JH, Jang AR, Kim DI, Park MJ, Lim SK, Kim MS, Park JH. PRMT1 mediates RANKL-induced osteoclastogenesis and contributes to bone loss in ovariectomized mice. Exp Mol Med. 2018; 50(8): 111..

15. Gong J, Peng C, Chen T, Gao B, Zhou H. Effects of theabrownin from pu-erh tea on the metabolism of serum lipids in rats: mechanism of action. J. Food Sci., 2010; 75 (6): H182-189

16. Shaban NZ, Talaat IM, Elrashidy FH, Hegazy AY, Sultan AS. Therapeutic Role of Punica Granatum (Pomegranate) Seed Oil Extract on Bone Turnover and Resorption Induced in Ovariectomized Rats. J Nutr Health Aging. 2017; 21(10):1299-1306.

17. Wend $P$, Wend K, Krum SA, Miranda-Carboni GA. The role of $W N T 10 B$ in physiology and disease. Acta Physiol, 2012; 204 (1): 34-51

18. Glass 2nd DA, Bialek $P$, Ahn JD, Starbuck M, Patel MS, Clevers H, Taketo MM, Long F, McMahon AP, Lang RA, Karsenty G. Canonical Wnt signaling in differentiated osteoblasts controls osteoclast differentiation. Dev. Cell, 2005; 8 (5): 751-764

19. Catalano A, Morabito N, Basile G, Brancatelli S, Cucinotta $D$, Lasco A. Zoledronic acid acutely increases sclerostin serum levels in women with postmenopausal osteoporosis. J. Clin. Endocrinol. Metab., 2013; 98 (5): 1911-1915,

20. Ke HZ, Richards WG, Li X, Ominsky MS. Sclerostin and Dickkopf-1 as therapeutic targets in bone diseases. Endocr. Rev., 2012; 33 (5): 747-783,

21. Mukhopadhyay M, Shtrom S, Rodriguez-Esteban $C$, Chen L, Tsukui T, Gomer L. Dickkopf1 is required for embryonic head induction and limb morphogenesis in the mouse. Dev Cell, 2001; 1 (3): 423-434

22. Glinka $A, W u W$, Delius $H$, Monaghan AP, Blumenstock $C$, Niehrs C. Dickkopf-1 is a member of a new family of secreted proteins and functions in head induction. Nature, 1998; 391 (6665): 357-362

23. Wu XB, Li Y, Schneider A, Yu W, Rajendren G, lqbal J. Impaired osteoblastic differentiation, reduced bone formation, and severe osteoporosis in nogginoverexpressing mice. J Clin Invest, 2003; 112: 924. 